\title{
Indirect (Mirror) Laryngoscopy: Valuable Laryngological Skill Going into Extinction?
}

\section{James E Toblh ${ }^{1}$, Olusola A Sogebi ${ }^{2}$, Taiwo 0 Adedej ${ }^{3 *}$ and Theophilus 0 Esan $^{4}$}

${ }^{1}$ Associate Professor and Head of Otorhinolaryngology Department, Ladoke Akintola

University of Technology/Teaching Hospital, Osogbo, Nigeria

${ }^{2}$ Consultant, Otorhinolaryngology Department, Olabisi Onabanjo Teaching Hospital, Sagamu, Nigeria

${ }^{3}$ Consultant, Otorhinolaryngology, Ladoke Akintola University of Technology/Teaching

Hospital, Osogbo, Nigeria

${ }^{4}$ Otorhinolaryngology Department, Federal Teaching Hospital, Ido-Ekiti, Nigeria

*Corresponding Author: Taiwo O Adedeji, Consultant, Otorhinolaryngology,

Ladoke Akintola University of Technology/Teaching Hospital, Osogbo, Nigeria.
Received: July 28, 2021

Published: September 22, 2021

(C) All rights are reserved by Taiwo 0

Adedejl., et al.

\section{Abstract}

Background: Indirect mirror laryngoscopy despite its relevance in Otorhinolaryngology practice most especially in the sub-Saharan where technology is still not readily available in most centres, appears to be going into extinction.

Methods: Two series of retrospective study were done, First series were patients that underwent indirect mirror laryngoscopy of larynx at a period when laryngeal endoscopy was not available (2011-2015) and the second series were patients that went through laryngeal examination when facilities of laryngeal endoscopy were available(2016-till June,2021). Questionnaires were also administered to the Otolaryngologists (consultants and residents in training)in this centre and three other sister departments in other teaching hospitals (one centre in Uk) to find out their skill and which of the two types of laryngeal examination they prefer and reasons for it. This research was done in a resource limited environment.

Results: In the first series, a total of 72 patients that needed laryngeal examination all had mirror indirect laryngoscopy (IDL) because there was no alternative. For the series 2 study, there were 37 IDL patients and 73 endoscopic patients. There ages and gender distributions were similar among the three groups (M:F were 1:2.1. 1:1.18, 1:1.09 respectively). Laryngitis was the most common specific pathological finding (13.9\%), IDL was not successful in 5.6\%and 4.2\%had over hanging epiglottis. Most patients with hoarseness had laryngeal tumour (33\%) and laryngitis $(28.6 \%)\left(X^{2}=48.923, p<0.001\right)$. fourteen doctors participated in the study, six were specialists while eight were resident doctors. Ten otolaryngologist still have relevant IDL skillful while four lack adequate skill. All respondent prefer laryngeal examination using endoscope and only 3 (21.4\%) still carry out IDL procedure mostly done when there is no electricity.

Conclusion: Examination of the larynx through Indirect laryngoscopy appears to be going into extinction in Otorhinolaryngological practice because of advent of endoscopic facility. The simplicity, non- energy depended, affordability, availability and ability to insulate the surgeon from undue medico-legal tussles makes it invaluable especially in developing countries of the world. It is recommended that every medical student rotating through ORL posting and otolaryngologists in training should be encouraged to master its use as an alternative in cases where scopes are not readily available.

Keywords: Laryngeal Evaluation; Indirect Mirror Laryngoscopy; Valuable Skill; Resource Limited Environment 


\section{Introduction}

Laryngeal examination is essential to diagnosis and management of the ENT patient [2,2]. Laryngeal disease, notably laryngeal cancer was responsible for 70 - 93\% of causes of upper airway obstruction that necessitated tracheostomy in many developing countries [3-7]. Laryngeal evaluation is also important in patients with labile airway and it is a useful adjunct in assessing patients with gastro-esophageal reflux, pulmonary tuberculosis, sarcoidosis, allergy, and neurologic diseases [1,2].

The larynx is relatively hidden and cannot be readily examined from the exterior hence the use of instruments, like flexible endoscopic laryngoscopy, video laryngoscopy, stroboscopy, rigid laryngoscopy and indirect mirror laryngoscopy (IDL) [8-11].

IDL is an inexpensive, non-invasive, non-energy depended-office procedure and permits examination of structures of the larynx [12]. IDL utilizes a small mirror, mounted on a stalk held at the back of the illuminated throat and overlooking the larynx, which is viewed indirectly in the mirror.

Historically however, IDL was one of the oldest and most commonly used procedures for laryngeal examination. It was first performed by Manual Garcia, a singer who visualized his vocal cords in a barber's shop through a set of mirrors placed on the wall $[13,14]$. All previous observations of the glottis and larynx had been performed by indirect vision with mirrors until 1895 when other means of laryngeal examination were introduced $[9,15]$.

An indirect mirror laryngoscopy may be indicated in patients who have voice problems (a breathy voice, hoarse voice, weak voice, raspy voice, or no voice) lasting more than 2 weeks [16], in evaluating patients with throat pain [12], difficulty in swallowing, a feeling of a lump in the throat and in those with injuries to the throat [12]. It is also indicated in long-term upper respiratory problems in smokers and in patients with masses in the head or neck area with clinical signs suspicious of cancer [16] and as a pre-operative evaluation in patients undergoing thyroidectomy or esophagectomy who are at risk of injury to recurrent laryngeal nerve $[17,18]$.

The newer methods including flexible endoscopic laryngoscope, video laryngoscopy, $70^{\circ}$ rigid scope and stroboscopy allow visualization of structures with better clarity, affords the patient more comfort, but are energy depended, have therefore superseded the use of IDL $[8,10,12]$. This study aims to document the number of laryngoscopic examinations done by indirect mirror examination and assess the level of its accuracy; and discuss the need to still include its practice in the curriculum of training for otolaryngologists while still assessing the use of a superior laryngeal endoscopy.

\section{Materials and Methods}

The study was a two series study, first series was when laryngeal endoscopy was not available and only mirror indirect laryngoscopy was. The second study series was when functional laryngeal scoping facilities was available. Questionnaires were also administered to ORL doctors to find out what method of laryngeal examination they prefer and are practicing and why. The first series study was a five year study (2011-2015) and the second series was from 2016 till June2021when laryngeal scoping facility was available.. This research was done in a tertiary health institution of a developing country.

Data was obtained from the clinical records of these patients. Information retrieved by the investigator from the record included patients' socio-demographics, indications for IDL, examination findings and the outcome.

\section{The procedure (IDL)}

Indirect mirror laryngoscopy is done with the examiner sits in front of a comfortably-seated patient. The detail procedure is explained to the patient assuring him that it is not an invasive procedure that may cause injury to him. The patient is asked to open his mouth and protrude his tongue, which is held by the examiner gently between his thumb and index finger with a piece of gauze while the patient is requested to continue to breathe gently. A warmed IDL mirror is now introduced in the mouth and held against the soft palate and patient asked to phonate by making a prolonged 'ee' or 'aa' sound. A head lamp or head mirror with a source of light is already worn on the examiners head and this light is focused on the laryngeal mirror, this brings the larynx including the vocal cords into view. Surface an anesthesia with xylocaine spray (10\%) may be used especially in patient that gag easily and excessive.

\section{Procedure (Laryngeal Endoscopy)}

This procedure is essentially the same in terms of patients handling and position. However instead of a laryngeal mirror, a rigid scope is introduced into the patient's throat. Surface anaesthesia may also be needed as in mirror indirect laryngoscopy. This facility offers a much better illumination of the larynx. 
Particular notes on IDL made included the location and type of epiglottis, the location, colour, and mobility of the true vocal cords and the status of the false vocal cords, the vallecula, the arytenoids cartilages, and the pyriform fossae.

Patients whose case records could not be located and those with incomplete information were excluded from the study.

The information obtained was fed into a spreadsheet and the data generated was analysed using SPSS version 14 (Illinois, USA). Descriptive analysis (as proportions), and comparison analysis with the Chi square test were performed and the results presented in tabular forms.

\section{Results}

For series one study (before the availability of scope) a total of 72 patients (IDL) had their complete records retrieved for the study. For the series 2 study, there were 37 IDL patients and 73 endoscopic patients. There ages and gender distributions were similar among the three groups (M:F were 1:2.1. 1:1.18, 1:1.09 respectively) table 1 .

\begin{tabular}{|c|c|c|c|}
\hline Variables & \multirow[t]{2}{*}{$\begin{array}{c}\text { IDL (\%) N } \\
=72 \\
\text { (Before } \\
\text { endoscopes) }\end{array}$} & \multicolumn{2}{|c|}{$\begin{array}{c}\text { IDL (N 37) Vs } 70^{\circ} \\
\text { scopes (N 73) } \\
\text { (during endoscopic } \\
\text { period) }\end{array}$} \\
\hline Age (Yrs) & & IDL & $70^{0}$ Scope \\
\hline$<20$ & - & - & 3 \\
\hline $20-29$ & 8 & 3 & 4 \\
\hline $30-39$ & 16 & 4 & 10 \\
\hline $40-49$ & 23 & 11 & 26 \\
\hline $50-59$ & 17 & 10 & 19 \\
\hline $60-69$ & 5 & 6 & 10 \\
\hline $70-79$ & 3 & 3 & 1 \\
\hline Total & 72 & 37 & 73 \\
\hline Sex & & & \\
\hline Male & 23 & 17 & 35 \\
\hline Female & 49 & 20 & 38 \\
\hline $\begin{array}{c}\text { Indication for Examina- } \\
\text { tion }\end{array}$ & & & \\
\hline Pre-thyroidectomy & 41 & & 33 \\
\hline Hoarseness & 21 & & 24 \\
\hline FBs/ lump sensation & 9 & & 13 \\
\hline Dysphagia & 1 & & - \\
\hline Chronic aspiration & - & & 3 \\
\hline Total & 72 & & 73 \\
\hline
\end{tabular}

Table 1: Age, Sex and indications for performing laryngeal examinations.

NB: FBs $=$ Foreign Bodies.
Major indications for IDL and endoscopic laryngeal examinations were; preoperative evaluation of thyroidectomy patients (56.9\%) and history of hoarseness (29.2\%). Details of age, sex distribution and other indications were as shown in table 1.

The IDL findings in all the patients (pre-thyroidectomy and specific indications) were as shown in figure 1 . Majority of the patients in this group had normal larynx, in patients with more than one abnormal finding; it was the more important finding that was recorded. Laryngitis was the most common specific pathological finding (13.9\% IDL), while IDL was not successful in 5.6\% and over hanging epiglottis precluded proper visualization in $4.2 \%$ of the patients.

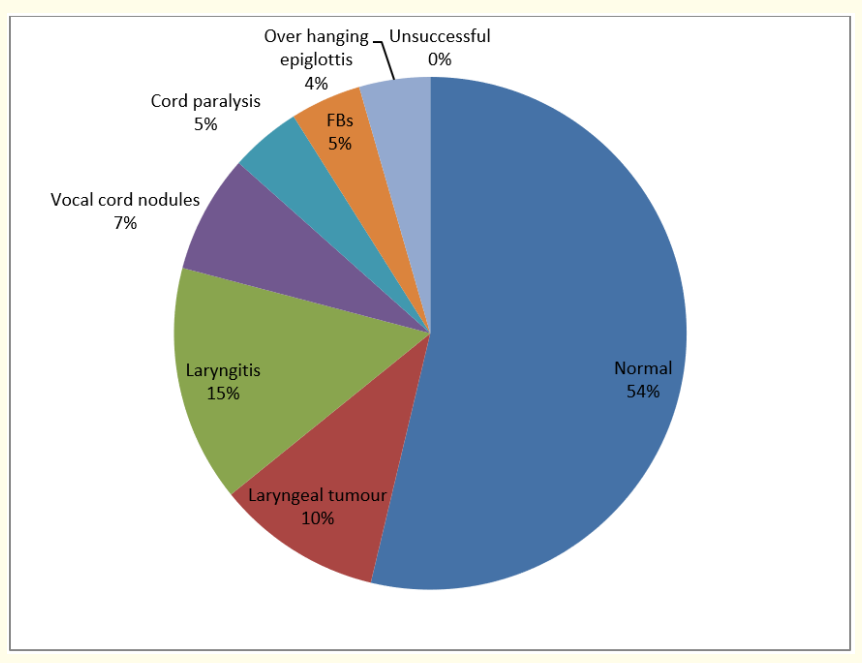

Figure 1: Findings at Indirect mirror laryngoscopy among the patients.

NB: FB = Foreign Bodies.

Table 2 shows the relevance of IDL in obtaining the laryngeal pathologies. Among the pre - thyroidectomy patients $78.0 \%$ had normal larynx, $14.6 \%$ had inconclusive report and $7.3 \%$ had other pathologies as shown in table 2 . Among those with specific indications, $77.4 \%$ had obvious pathologies, $19.4 \%$ were normal larynx and $3.2 \%$ was inconclusive.

Most patients (33\%) with hoarseness had laryngeal tumour and laryngitis $\left(28.6 \%\right.$. $\left(X^{2}=48.923, p<0.001\right)$. In $5.6 \%$ of the patients, IDL was not successful. 


\begin{tabular}{|c|c|c|c|c|c|}
\hline Findings & $\begin{array}{c}\text { Pre-thy- } \\
\text { roidectomy }\end{array}$ & $\begin{array}{c}\text { Fb/ } \\
\text { lump } \\
\text { sensa- } \\
\text { tion }\end{array}$ & $\begin{array}{c}\text { Dys- } \\
\text { phagia }\end{array}$ & $\begin{array}{c}\text { Hoarse- } \\
\text { ness }\end{array}$ & Total \\
\hline Normal & 32 & 3 & 1 & 2 & 38 \\
\hline Laryngitis & 2 & 2 & 0 & 6 & 10 \\
\hline $\begin{array}{c}\text { Laryngeal } \\
\text { tumour }\end{array}$ & 0 & 0 & 0 & 7 & 7 \\
\hline Vocal nodules & 1 & 0 & 0 & 3 & 4 \\
\hline $\begin{array}{c}\text { Vocal cord } \\
\text { palsy }\end{array}$ & 0 & 0 & 0 & 3 & 3 \\
\hline $\begin{array}{c}\text { Overhanging } \\
\text { epiglottis }\end{array}$ & 2 & 1 & 0 & 0 & 3 \\
\hline Fbs & 0 & 3 & 0 & 0 & 3 \\
\hline $\begin{array}{c}\text { Unsuccessful } \\
\text { IDL }\end{array}$ & 4 & 0 & 0 & 0 & 4 \\
\hline Total & 41 & 9 & 1 & 21 & 72 \\
\hline
\end{tabular}

Table 2: Indirect mirror laryngoscopy findings across different indications.

The physicians (Otolaryngologists) ages, years of experience and frequency of IDL or Endoscopy were compared. There were 14 doctors in four ORL centres that were interviewed. Two females and twelve male, six are specialists consultant and eight resident doctors. Four (28.57\%) have practice for 10 years and below, 7 (50\%) have practiced for 11 - 20 years and 3 (21.43\%) have more than 20 years of experience Ten $(71.4 \%)$ otolaryngologist still have good IDL skills while 4 (28.6) lack IDL skill and those without experience are all resident doctors. All respondent (100\%) prefer laryngeal endoscopy to IDL, only 3 mostly senior consultants still do IDL and only when there is no electricity. Thirteen (92.8) otolaryngologists however still want IDL skill retained in otolaryngological practice.

\section{Discussion}

Fewer numbers of IDLs in the second series of study 37 (34.3\%) while scoping was $73(65.7 \%)$ suggests that the procedure is no more popular and may be going into extinction. However it is yet important that the examination/procedure be encouraged and its skill be well established among otolaryngologists, medical students and medical officers with bias in otorhinolaryngology especially in regions where resources are limited. Despite the fact that there are other more sensitive and more accurate endolaryngoscopes; every
Otolaryngologist should be able to examine the larynx using the mirror effectively, just the same way that despite the proliferation of different sophisticated simpler methods of performing tonsillectomy, every ENT surgeon is still expected to do tonsillectomy by dissection. In the second study series, IDL were predominantly now being done by only very few ones and only when there was no electricity for laryngeal endoscope whereas in the first series all participated actively in the procedure, the younger ones striving to gain the expertise. IDL may be particularly useful because it is quick to perform and does not require sophisticated equipment, has modest sensitivity in diagnosing lesions in the larynx There was significant correlation between indications and mirror laryngoscopy findings $\left(\mathrm{X}^{2}=28.530(\mathrm{p}<0.001)\right.$, this shows its relevance at detecting laryngeal pathologies in the study. In fact, indirect mirror laryngoscopy (IDL), despite advances in technology has remained a relevant and useful tool in otorhinolaryngologic practice [19-22]. This is particularly so in low and middle income countries of the world where modern advanced diagnostic technologies are not readily available [20]. This procedure is particularly useful and reliable in evaluating a relatively inaccessible part of the body for early diagnosis of potentially life threatening laryngeal conditions [19].

IDL is often performed for pre-operative evaluation of the larynx in patients scheduled for thyroid surgeries and this constituted the most common indication as found in this study, like a previous studies [19]. This may not be unconnected with increasing litigation among patients that undergo surgical procedures in our country. A researcher had reported that, recurrent laryngeal nerve palsy is one of the leading reasons for medicolegal litigation of surgeons due to its attendant reduced quality of life [21].

The laryngeal mirror is the most readily-available tool to assess the larynx in most health facilities in resource limited areas of the world. Thus IDL is a clinic procedure that is quick, available and also affordable in those environments. Resident in ORL, medical officers and medical students rotating through ORL need to learn and become skillful with the procedure and prevent it from going into extinction [19,20,22].

Hoarseness was the second major indication in both groups in this study and the leading complaints among these patients. It was 
also the most common indication for direct laryngoscopy in those who presented with laryngeal symptoms. Hoarseness is often a manifestation of vocal cord lesion which will subsequently need to be visualized, thus hoarseness remains a major indication for both indirect and direct laryngoscopy. Other studies have also reported hoarseness as a major symptom of laryngeal disease and its persistence for more than two or three weeks will warrant complete evaluation $[16,23,24]$. Other specific indications from this study were foreign body (FBs)/lumpy sensation in the throat, chronic aspiration and dysphagia. These indications are pointers to the usefulness of indirect mirror laryngoscopy not only in the evaluation of laryngeal disease but also for pharyngeal and esophageal diseases in resource limited countries of the world [19].

Pre- operative laryngoscopy is particularly relevant in this environment where intra - operative monitoring of patients is suboptimal compared to other places with modern monitoring equipment $[10,21,26]$. It is pertinent to note that $7.3 \%$ of pre-thyroidectomy patients had laryngeal pathologies (laryngitis and vocal cord nodules) which would have been missed were IDL not performed. Our center is a tertiary center with some modern equipment, but all our outreach Centres and several others in our country with inadequate facilities and poor electricity supply can only evaluate laryngeal pathologies with mirror examination and hence such a relevant tool should be prevented from going into extinction.

The limitations of IDL include the mild discomfort it inflicts on patients, difficulty to assess the larynx in subjects with overhanging epiglottis, those with excessive gag reflex, the terrified individual, and in children especially less than ten years of age. In the present study, IDL was not successful in some of our patients due to overhanging epiglottis and excessive gag reflex and anterior commissure was not visualize in up to $37.5 \%$. Such patients were re-evaluated with $70^{\circ}$ scopes. Barker, et al. [26] compared mirror examination with a rigid lens system and concluded that the mirror is a useful screening tool so long as strict examination criteria are used and that the rigid rod adds further diagnostic information in those patients who cannot be evaluated with a mirror.

Majority of the patients with specific indications, laryngeal symptoms, foreign body sensations, and dysphagia had obvious pathologies on mirror laryngoscopic assessment. Schwartz., et al. [27] recommended that the clinicians should visualize the patient's larynx, when hoarseness fails to resolve by a maximum of three months after onset or irrespective of duration if a serious underly- ing cause is suspected and that visualization of the larynx should precede radiological investigation or voice therapy prescription. This shows that despite some limitations mirror laryngoscopy still retain its usefulness in laryngeal evaluation.

Laryngeal tumour was one of the common finding among patients with specific indications from this study in agreement with previous published studies [29,23,27]. The need to thoroughly evaluate all patients with laryngeal symptoms especially patients with hoarseness $[16,19,23,27,28]$ cannot be over-emphasized. Hoarseness is a major symptom of laryngeal disease and persistent hoarseness may be an early symptom of such sinister lesions as cancer of the larynx, nasopharynx and bronchogenic carcinoma [23]. Of particular note is one of the patients that had vocal cord paralysis secondary to recurrent laryngeal nerve injury following thyroidectomy. There was no record of preoperative laryngoscopy in that patient because the procedure was done in a remote center where facilities were not adequate. In such a center IDL can be easily undertaken. Recurrent laryngeal nerve paralysis after thyroid gland surgeries have been severally reported [29]. However, preoperative recurrent laryngeal nerve paralysis has been found to be present in $70 \%$ of patients with invasive thyroid disease and in $0.3 \%$ of patients with noninvasive thyroid disease [18]. Symptomatic voice assessment and radiographic evaluation are insufficient and laryngoscopic examination is essential and recommended for the detection of vocal cord paralysis preoperatively [18]. This will particularly be of benefit to the attending physician in resource limited environment as a safe-guard to medicolegal confrontations.

\section{Conclusion}

Fewer numbers of IDLs being done as shown by the present study suggests that the procedure may be going into extinction. The simplicity, non-energy depended, affordability, availability in any setting couple with its ability to insulate the surgeon from undue medico-legal tussles makes it invaluable in low income countries of the world. It is therefore recommended that it should be a priority curriculum just as rural outreach exposures are, among Medical students going through otolarynglogical postings and residents in Otolaryngology. This will preserve this valuable skill in otolaryngological practice.

\section{Bibliography}

1. Holsinger FC., et al. "Examination of the Larynx and Pharynx". The New England Journal of Medicine 358 (2008): e2. 
2. Ridley MB., et al. "Office diagnostic techniques. The adult patient". In: Fried MP ed. The larynx; a multidisciplinary approach". 2nd ed. St. Louis: Mosby, (1996): 57-64.

3. Eziyi JA., et al. "Tracheostomy in south western Nigeria: Any change in pattern?" Journal of Medicine and Medical Science 2.7 (2011): 997-1002.

4. Iseh KR and Malami SA. "Patterns of head and neck cancers in Sokoto". Nigerian Journal of Otorhinolaryngology 3 (2006): 77-83.

5. Nwawolo CC., et al. "Pattern of head and neck cancers among Nigerians in Lagos". West African Journal of Medicine 20.2 (2001): 111-116.

6. Nwaorgu OG., et al. "Laryngeal carcinoma: clinical features seen at University college hospital Ibadan". Tropical Doctor 32.4 (2002): 236-237.

7. Ahmad BM and Pindiga UH. "Malignant neoplasms of the ear, nose and throat in northeastern Nigeria". Highland Medical Research Journal 2.1 (2004): 45-48.

8. Bailey B. “Laryngoscopy and laryngoscopes--who's first? The forefathers/four fathers of laryngology". The Laryngoscope 106.8 (1996): 939-943.

9. Hirsch NP., et al. "Alfred Kirstein. Pioneer of direct laryngoscopy". Anaesthesia 41.1 (1986): 42-45.

10. Szmeja Z and Kruk-Zagajewska A. "Diagnosis of laryngeal cancer”. Otolaryngology Polish 49.5 (1995): 395-409.

11. Grabas CS., et al. "The relevance of mirror examination in modern Otorhinolaryngology". UgeskrLaeger 163.47 (2001): 6586-6589.

12. Fowler C and Dumas C. "Indirect mirror laryngoscopy". In: Pfenninger JL, ed. Pfenninger and Fowler's Procedures for Primary Care. 3rd ed. Philadelphia, Pa: Mosby Elsevier (2010): chap 79.

13. García M. "Observations on the Human Voice". Proceedings of the Royal Society of London 7 (1855): 399-410.

14. Radomski T. “Manuel García (1805-1906): A bicentenary reflection”. Australian Voice 11 (2005): 25-41.

15. Koltai PJ and Nixon RE. "The story of the laryngoscope". Ear, Nose, and Throat Journal 68.7 (1989): 494-502.

16. Rosen CA., et al. "Evaluating hoarseness: keeping your patient's voice healthy”. American Family Physician 57.11 (1998): 2775-2782.
17. Johnson PR., et al. "Indirect laryngoscopic evaluation of vocal cord functions in patients undergoing transhiatalesophagectomy". Journal of the American College of Surgeons 178.6 (1994): 605-608.

18. Randolph GW and Kamani D. "The importance of preoperative laryngoscopy in patients undergoing thyroidectomy: voice, vocal cord function, and the preoperative detection of invasive thyroid malignancy". Surgery 139.3 (2006): 357-362.

19. Olaosun AO., et al. "Mirror Laryngoscopy: a Review of 43 cases". Surgery Journal 4.2 (2009): 29-34.

20. Grabas CS., et al. "The relevance of mirror examination in modern otorhinolaryngology". UgeskrLaeger 163.47 (2001): 65866589.

21. Benjamin B. "Indirect laryngeal photography using rigid telescopes”. Laryngoscope 108.2 (1998): 158-161.

22. Calhoun KH., et al. "Teaching indirect mirror laryngoscopy". Otolaryngology-Head and Neck Surgery 100.1 (1989): 80-82.

23. Nwaorgu OG., et al. "Hoarseness in adult Nigerians: a University College Hospital Ibadan experience". Nigerian Journal of Medicine 13.2 (2004): 152-155.

24. Nwaorgu OGB., et al. "Hoarseness in Children: Clinical Spectrum as seen in the Otorhinolaryngology Department of two Nigerian Tertiary Health Institutions". Nigerian Journal of Otorhinolaryngology 1.1 (2004): 6-10.

25. Sayyahmelli M., et al. "Value of Laryngoscopy before and After Thyroidectomy". RMJ 34.1 (2009): 89-91.

26. Barker $\mathrm{M}$ and Dort JC. "Laryngeal examination: a comparison of mirror examination with a rigid lens system". Journal of Otorhinolaryngology 20.2 (1991): 100-103.

27. Schwartz SR., et al. "Clinical practice guideline: hoarseness (dysphonia)". Otolaryngology-Head and Neck Surgery 141 (2009): S1-S31.

28. Baitha S., et al. "Predisposing Factors and Aetiology of Hoarseness of Voice”. IJOHNS 56.3 (2004): 186-190.

29. Thermann M., et al. "Recurrent laryngeal nerve paralysis after thyroid gland operations. Etiology and Consequences". Chirurg 69.9 (1998): 951-956.

\section{Volume 5 Issue 10 October 2021} (C) All rights are reserved by James E Toblh., et al. 